\title{
Brand Value Co-creation and Brand Performance
}

\author{
Wenjian Zheng ${ }^{a}$, Zhihua Lian ${ }^{\text {b,* }}$ \\ Xiamen University Tan Kah Kee College, Zhangzhou 363105, China \\ azwjstrategy@xujc.com, ${ }^{b}$ Corresponding Author:lawrancelian@xujc.com
}

\begin{abstract}
Keywords: Brand Information Display; Quality of Service Experience; Perception of the Brand Value; Brand Performance.
\end{abstract}

\begin{abstract}
The purpose of this paper is to explore the brand value co-creation, and test mediating effect of quality of service experience and the moderation effect of perception of the brand value on the relationship between brand information display and brand performance. In order to exam the model we defined, SEM and SPSS are used to analyze the data collected from the sample of 400 customers on the Chinese mainland. Results demonstrate that brand information display can affect brand performance through mediator of quality of service experience. In addition, perception of the brand value moderating impacts brand information display and brand performance, and also plays moderation effect between perception of the brand value and brand performance. This paper demonstrates the internal relationship between brand value co-creation on the basis of characteristics and offers ways for organizations to improve organizational performance.
\end{abstract}

\section{Introduction}

Nowadays, customers are not passive customers anymore. They have been actively engaged in virtual communities, such as exchanging information, suggesting others about products, brands, services or any information. They even active in commenting on products, brands, or services. This will guide firms and other customers to new variety ideas of products, brands, and services, which is also suitable with customers' needs. It is interpreted that there is transformation shift for customers' role. They have turned to "Proactive Consumer". They become value co-partner for firms and others in the entire service-value chain. As a consequence, many brands or firms try to fortify their relationship with customers by investing more in online brand community. Therefore, Co-creation value of the experience can develop products by using customer's creativity and thinking pattern. It's make customer's participation became the value of brand. Completely transform the brand value becomes irreplaceable competitive. While manufacturer become positive brand image by using the pattern, demander's sense of value will increasing, in order to enhance consumers purchase intention. Although the branding literature has recently shifted research focus form consumer markets to organizational markets, the attention paid to industrial services branding is still not enough. Our purpose here is to examine how consumers and consuming groups influence the value co-creation process.

\section{Literature Review and Hypotheses}

\subsection{Brand Value Co-creation}

Marketing theory is increasingly moving away from understanding value as produced by firms in isolation from their consumers towards perceiving value as something that firms, consumers and other stakeholders co-create in collaboration (Gronroos, 2011; Vargo and Lusch, 2008). Wikstro (1996) suggests that marketing philosophy does not focus on how companies createvalue for consumers, but rather on how they create value with consumers, signalling a change from a producerconsumer perspective to a co-creation perspective-as it is referred to within service-dominant logic of marketing, in which the role of company and consumer has been recast from producer-consumer to co-creators of value (Vargo and Lusch, 2008). 
Bernard (2015) developed a framework based on brand value co-creation and used this framework to analyse the online collaboration promoted by the carmaker Fiat with its brand community of Alfa Romeo enthusiasts. Furthermore, Zhang Jing \& Deng Hui(2013) identifies key dimensions of brand value co-creation and also resents research framework based on qualitative interviews with 3 industrial services firms and validates the conceptual model addressing the impact of different dimensions of brand value co-creation activities upon brand performance. We define it as a value co-creation activities process on firm-employees, firm-customers, employees-customers and firm-other stakeholders interfaces are involved in order to build services brand. The following three dimensions (band information display, quality of service experience, perception of the brand value) help to build good inter-organizational relationship at organizational level and accumulate internal brand equity, to improve good interaction with other members, force employees to improve service experience quality and personal relationship with customers. All these activities will positively impact brand value perception and final brand performance.

\subsection{Mediating effects of Quality of Service Experience}

Recently, there has been increasing interest in creating "experiences" for customers, particularly for those in the service sector. Along these lines, a number of authors argue that the service economy has been transformed into an attention economy (Davenport \& Beck, 2002), entertainment economy (Born \& Wolf, 1999), an emotion economy (Gob'e \& Zyman, 2001), or an experience economy (Pine \& Gilmore, 1998). The authors indicate that as commoditization of many service offerings continues, companies must find new ways to achieve a competitive advantage particularly by focusing on design and management of customers' experiences.

Quality of Service Experience is a mediating effect between the brand information display and performance for service brand by creating and managing (Morrison, S \& Crane F G, 2007). Bernard and Stefano (2015) pointed out brand experience not only relate to consumer perception but also consumer intention. Brand community members play a dynamic role in the value co-creation process by acting as providers and beneficiaries, thereby co-creating value for themselves, for brand communities, and for organizations (Pongsakornrungsilp and Schroeder, 2011).Parasuraman, Zeithaml, and Berry (1988) define service quality as "the differences between customer expectations and perceptions of service,"and argued that measuring service quality as the difference between perceived and expected service was a valid way and could make management to identify gaps to what they offer as services. we believe that quality of service experience as a critical mechanism explaining the effects of the brand information display and on brand performance; that is, brand information display shapes brand performance through the quality of service experience. Therefore, we propose the following:

H1: Quality of service experience mediates the effects of brand information display on brand performance.

\subsection{Moderating effects of Perception of the Brand Value}

Moderating effects of perception of the brand value according to balance theory (Heider, 1958), which illustrates people's attitudinal changes, people tend to maintain a psychologically balanced state. Dodds and Monroe (1985) defined perceived value as a trade-off between buyers' perceptions of quality and sacrifice, and it is positive when perceptions of quality are greater than the perceptions of sacrifice. Perceived value refers to a consumer's overall assessment of utility based on perceptions regarding what is received and what is given (Zeithaml, 1988). Marketing researchers pay great attention to perceived value of a brand because consumer brand choice largely depends on how much the consumers value the brand (Dew \& Kwon, 2010; Sheth, Newman, \& Gross, 1991; Sweeney \& Soutar,2001). Because an imbalanced state produces tension, people change their attitudes to create a balanced state. Such a state exists when the relations among entities fit together harmoniously (Dalakas \& Levin, 2005). If the result of multiplying all affect valences (positive or negative) of all the relations is positive, there exists a balanced state (Dean, 2002). Perceived brand value is relatively more critical for luxury brands because consumers purchase luxury brands when they perceive sufficient value that compensates for higher price (Tynan, McKechnie, \& Chhuon, 2010). The higher brand value differentiated from other brands is one of the luxury brands' key characteristics (Fionda 
\& Moore, 2009), and consumers purchase a luxury product because it represents their value (Vigneron \& Johnson, 2004). Perceived value has been argued to be the most important indicator to forecast purchase intentions and has been viewed as one of the most important measures for gaining a competitive advantage (Bolton \& Drew, 1991; Cronin, Brady, \& Hult, 2000; Dodds, Monroe, \& Grewal 1991; Kerin, Jain, \& Howard, 1992; Parasuraman, 1997; Zeithaml, 1988).Thus, the following hypothesis is developed.

H2: Perception of the Brand Value moderate the relationship between brand information display and brand performance.

H3: Perception of the Brand Value moderate the relationship between quality of service experience and brand performance.

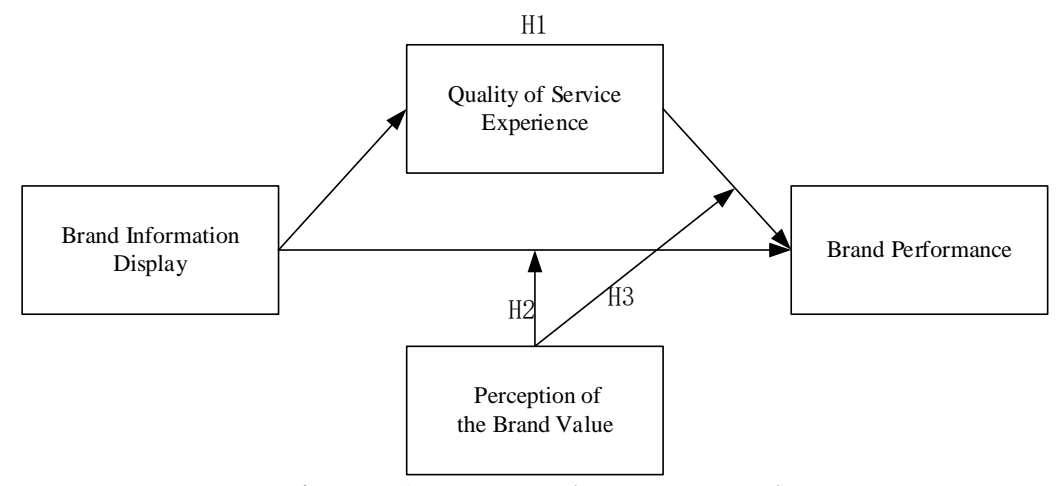

Figure 1. Research Framework

\section{Samples and procedures}

A cross-sectional research design was used in this study. In order to know if this model can be supported in the sample of the firm-customers, we used convenience sampling and occasional sampling method and tested the hypotheses with the sample survey. Researchers obtained data on customers in mainland China. We received 425 questionnaires (92 percent), among which 400 are valid questionnaires (86percent). All subjects who joined in this study did on a voluntary basis with ensured confidentiality.

\section{Results and Discussion}

\subsection{Measurement Model}

When self-report questionnaires are used to collect data at the same time from the same participants, common method variance (CMV) may be a concern. We test CMV loads all items from each of the constructs into an exploratory factor analysis to see whether one single factor does emerge or whether one general factor does account for a majority of the covariance between the measures; if not, the claim is that $\mathrm{CMV}$ is not a pervasive issue. The expected ex post model showed good fit indexes (RMSEA=0.049; NFI=0.942; CFI=0.970; GFI=0.942; IFI=0.971). Nevertheless, this model did not yield a significantly better fit to the data than ex ante CMV.

First, we tested the empirical distinctness of the three model of value co-creation measures (i.e., brand image, experience value, perceived value and brand performance). The proposed three-factor model provided a good fit $\left(\chi^{2}=251.536, \mathrm{df}=128, \mathrm{p}=0.01\right)$, comparative fit index (CFI=0.970), root mean square error of approximation (RMSEA=0.049), and fit the data significantly better than a one-factor model or any of the three possible two-factor models combining two brand value co-creation constructs into one factor (all $\mathrm{p}<.01$ ). Second, we examined the distinctiveness of hope from each of the three brand value co-creation constructs. In all cases, the two-factor models separating hope from the brand value co-creation variable were superior to the one-factor model (each $\mathrm{p}<.001$ ). Finally, we assessed the quality of the entire measurement model that included the three brand value co-creation factors, brand image, experience value, perceived value and brand 
performance. This model fit the data well and the separation of hope into the agency and pathways factors did not enhance the model fit.

Table 1. Measurement Model

\begin{tabular}{|c|c|c|c|c|c|c|c|c|c|}
\hline \multirow{2}{*}{ Model } & \multirow{2}{*}{ Construct } & \multicolumn{8}{|c|}{ Fit Index } \\
\cline { 3 - 10 } & & $\chi^{2}$ & df & $\chi^{2} /$ df & GFI & CFI & NFI & RMSEA & IFI \\
\hline Model1 & one-factor & 1511.162 & 170 & 8.889 & 0.655 & 0.679 & 0.654 & 0.141 & 0.681 \\
\hline Model2 & two-factor & 267.084 & 133 & 2.008 & 0.941 & 0.968 & 0.939 & 0.050 & 0.968 \\
\hline Model3 & three-factor & 251.536 & 128 & 1.965 & 0.942 & 0.970 & 0.942 & 0.049 & 0.971 \\
\hline
\end{tabular}

Note: $n=400$

\subsection{Descriptive Statistics and Bivariate Correlations}

Table 2 presents AVE, Composite reliability estimates, and bivariate correlations of the research variables. The correlation matrix is arranged by traits brand information display and brand performance $\left(0.400^{* *}\right)$; brand information display and quality of service experience $\left(0.516^{* *}\right)$; quality of service experience and brand performance $\left(0.551^{* *}\right)$; perception of the brand value and brand performance $(0.728 * *)$.

Table 2. Descriptive Statistics and Bivariate Correlations

\begin{tabular}{|c|c|c|c|c|c|c|c|c|c|c|c|c|}
\hline \multicolumn{2}{|c|}{ Measures } & AVE & $\begin{array}{c}\text { Composite } \\
\text { Reliability }\end{array}$ & 1 & 2 & 3 & 4 & 5 & 6 & 7 & 8 & 9 \\
\hline 1 & Gender & - & - & - & & & & & & & & \\
\hline 2 & MS & - & - & -.029 & - & & & & & & & \\
\hline 3 & AGE & - & - & $-.143^{* *}$ & $.605^{* *}$ & - & & & & & & \\
\hline 4 & EDU & - & - & -.015 & -.044 & -.073 & - & & & & & \\
\hline 5 & JOB & - & - & $.125^{*}$ & $-.144^{* *}$ & $-.158^{* *}$ & $-.116^{*}$ & - & & & & \\
\hline 6 & BID & 0.51 & 0.88 & .031 & .086 & $.117^{*}$ & -.006 & .022 & - & & & \\
\hline 7 & QSE & 0.56 & 0.87 & -.012 & .055 & $.182^{* *}$ & .039 & -.064 & $.516^{* *}$ & - & & \\
\hline 8 & PBV & 0.55 & 0.83 & -.006 & $.124^{*}$ & $.219^{* *}$ & .048 & -.067 & $.463^{* *}$ & $.719^{* *}$ & - & \\
\hline 9 & BP & 0.55 & 0.83 & -.015 & $.140^{* *}$ & $.258^{* *}$ & .069 & -.088 & $.400^{* *}$ & $.551^{* *}$ & $.728^{* *}$ & - \\
\hline
\end{tabular}

Note: MS=Marital Status; BID=Brand Information Display; QSE=Quality of Service Experience; $\mathrm{PBV}=$ Perception of the Brand Value; $\mathrm{BP}=$ Brand Performance.

${ }^{*} \mathrm{p}<.05 .{ }^{* *} \mathrm{p}<.01 . * * * \mathrm{p}<.001$.

\subsection{Hierarchical regression-mediating effect}

To identify potential mediator of the relationship between brand information display and brand performance, three multiple regression models were followed next to test for mediation (Baron and Kenny, 1986). First, a significant relationship was established between brand information display and brand performance. Then a significant association was shown between brand information display and quality of service experience. At the third step, we use brand performance as the criterion variable in a regression equation; both brand information display and quality of service experience were entered. The brand information display can still find the significant relations with brand performance, but the influence became much weaker, thus partial mediation of quality of service experience is indicated, which is shown in Table 3. 
Table 3. Mediating multiple regression results.

\begin{tabular}{|c|c|c|c|}
\hline \multirow{2}{*}{ Variables } & \multicolumn{3}{|c|}{ Model1 } \\
\cline { 2 - 4 } & BP & QSE & BP \\
\hline Gender & -0.033 & -0.032 & -0.082 \\
\hline marital status & 0.033 & -0.012 & -0.035 \\
\hline Age & $0.252^{* * *}$ & 0.068 & $0.243^{* * *}$ \\
\hline Education & $0.188^{* * *}$ & 0.085 & $-0.165^{* * *}$ \\
\hline Job & -0.086 & 0.026 & 0.010 \\
\hline BID & $0.076^{* * *}$ & $0.236^{* * *}$ & $0.071^{*}$ \\
\hline QSE & & & $0.023^{* * *}$ \\
\hline $\mathrm{R}^{2}$ & $0.091^{* * *}$ & $0.233^{* * *}$ & $0.197^{* * *}$ \\
\hline Adj-R & $0.084^{* * *}$ & $0.196^{* * *}$ & $0.155^{* * *}$ \\
\hline $\mathrm{F}$ & $2.956^{* * *}$ & $25.618^{* * *}$ & $2.685^{* * *}$ \\
\hline
\end{tabular}

Notes: $\mathrm{n}=400$; Significant at:* $\mathrm{p}<.05 .{ }^{* *} \mathrm{p}<.01 .{ }^{* * *} \mathrm{p}<.001$.

$\mathrm{BID}=$ Brand Information Display; QSE=Quality of Service Experience; PBV= Perception of the Brand Value; $\mathrm{BP}=$ Brand Performance.

\subsection{Hierarchical regression-moderating effect}

As shown in Table 4 and 5, we first test the moderating effect of perception of the brand value between brand information display and brand performance. In the control of the respondent's gender, age, education, job, marital status, the interaction of the preference of brand information display and perception of the brand value is significant $(\beta=0.020, p<0.05)$; The moderating effect of perception of the brand value is identified, which means once perception of the brand value has stronger preference to chase for brand logo, their brand effort will lead to stronger performance. At last we test the interaction of the preference of quality of service experience and perception of the brand value on brand performance, which is significant $(\beta=0.028, \mathrm{p}<0.05)$; The moderating effect of perception of the brand value is identified, which means once service experience has stronger preference to chase for brand performance and independence, their perception of the brand value effort will improve their performance in organization.

Table 4. Moderating hierarchical multiple regression results1

\begin{tabular}{|c|c|c|c|c|}
\hline \multirow{2}{*}{ Variables } & \multicolumn{4}{|c|}{ Brand Performance } \\
\cline { 2 - 5 } & Model2 & Model3 & Model4 & Model5 \\
\hline Gender & 0.031 & 0.014 & 0.006 & 0.004 \\
\hline marital status & -0.031 & -0.041 & -0.021 & -0.022 \\
\hline Age & $0.281^{* * *}$ & $0.237^{* *}$ & $0.116^{* *}$ & $0.115^{* *}$ \\
\hline Education & 0.084 & 0.081 & 0.043 & 0.041 \\
\hline Job & -0.042 & -0.057 & -0.026 & -0.027 \\
\hline BID & & $0.377^{* * *}$ & $0.082^{*}$ & $0.082^{*}$ \\
\hline PBV & & & $0.664^{* * *}$ & $0.661^{* * *}$ \\
\hline BID* PBV & & & & $0.020^{*}$ \\
\hline $\mathrm{R}^{2}$ & $0.077^{* * *}$ & $0.217^{* * *}$ & $0.548^{* * *}$ & $0.548^{* * *}$ \\
\hline $\mathrm{AdjR}^{2}$ & $0.065^{* * *}$ & $0.205^{* * *}$ & $0.540^{* * *}$ & $0.539^{* * *}$ \\
\hline $\mathrm{F}$ & $6.583^{* * *}$ & $70.105^{* * *}$ & $204.255^{* * *}$ & $136.058^{* * *}$ \\
\hline
\end{tabular}

Notes: $\mathrm{n}=400$; Significant at:*p $<.05 .{ }^{* *} \mathrm{p}<.01 .{ }^{* * *} \mathrm{p}<.001$.

$\mathrm{BID}=$ Brand Information Display; QSE=Quality of Service Experience; PBV= Perception of the Brand Value; $\mathrm{BP}=$ Brand Performance. 
Table 5. Moderating hierarchical multiple regression results2

\begin{tabular}{|c|c|c|c|c|}
\hline \multirow{2}{*}{ Variables } & \multicolumn{4}{|c|}{ Brand Performance. } \\
\cline { 2 - 5 } & Model6 & Model7 & Model8 & Model9 \\
\hline Gender & 0.031 & 0.018 & 0.008 & 0.007 \\
\hline marital status & -0.031 & 0.016 & -0.015 & -0.019 \\
\hline Age & 0.281 & $0.157^{* *}$ & $0.113^{* *}$ & 0.114 \\
\hline Education & 0.084 & 0.059 & 0.041 & 0.040 \\
\hline Job & -0.042 & -0.023 & -0.021 & -0.023 \\
\hline QSE & & $0.518^{* * *}$ & 0.050 & 0.052 \\
\hline PBV & & & $0.666^{* * *}$ & $0.666^{* * *}$ \\
\hline QSE*PBV & & & & $0.028^{*}$ \\
\hline $\mathrm{R}^{2}$ & $0.077^{* * *}$ & $0.334^{* * *}$ & $0.544^{* * *}$ & $0.545^{* * *}$ \\
\hline AdjR $^{2}$ & $0.065^{* * *}$ & $0.324^{* * *}$ & $0.536^{* * *}$ & $0.535^{* * *}$ \\
\hline $\mathrm{F}$ & $6.583^{* * *}$ & $151.675^{* * *}$ & $200.691^{* * *}$ & $133.897^{* * *}$ \\
\hline
\end{tabular}

Notes: $\mathrm{n}=400$; Significant at: ${ }^{*} \mathrm{p}<.05 .{ }^{* *} \mathrm{p}<.01 .{ }^{* * *} \mathrm{p}<.001$.

$\mathrm{QSE}=$ Quality of Service Experience; $\mathrm{PBV}=$ Perception of the Brand Value; $\mathrm{BP}=\mathrm{Brand}$ Performance.

\section{Conclusion}

This study extends the literature by examining the consequences of band information display, quality of service experience, perception of the brand value and brand performance. As hypothesized, band information display variables can affect quality of service experience and also has direct and indirect effects on brand performance mediated by quality of service experience. Moreover, we have deepened and expanded our understanding of the relationship between band information display and brand performance, quality of service experience and brand performance by the moderating effects of perception of the brand value from one aspect to another. In general, this paper contributes to the ongoing efforts to understand the strategic management aspect of brand value co-creation.

\section{Limitations and Future Work}

Our study has several limitations. First, our results are based on cross-sectional data. Thus, we cannot make any empirically based causal conclusions. Therefore, current study results cannot be extrapolated to describe the experiences or circumstances of brand value co-creation in other areas. In addition, all variables are concerned with perception or self-behaviors, which is difficult to be assessed by others; that may cause single source bias. We need to consider this bias in research design and try to survey team member and their customer in further study to get more accurate data and avoid common variance.

\section{Acknowledgments}

At the point of finishing this paper, I'd like to express my sincere thanks to all those who have lent me hands in the course of my writing this paper. First of all, I'd like to take this opportunity to show my sincere gratitude to myself. Secondly, I'd like to express my gratitude to my friends who offered me references and information on time. Without their help, it would be much harder for me to finish my study and this paper.

\section{Funding}

This research was supported by Education and Sciences Research Project Fund for Youth and Middle-aged Teachers in Fujian Higher Education Institutions, China (JAS150773). Humanity and Social Sciences Research Foundation of Ministry of Education of China (15YJC630069), Sciences 
Research Talents Project Fund for Outstanding Young Teachers in Fujian Higher Education Institutions,China(2016023).

\section{References}

[1] B. Cova, S. Pace and P. S. le N, Brand volunteering: Value co-creation with unpaid consumers, Marketing Theory 15 (2015), no. 4, 465-485.

[2] S. Morrison and F. G. Crane, Building the service brand by creating and managing an emotional brand experience, Journal of Brand Management 14 (2007), no. 5, 410-421.

[3] S. Novani and K. Kijima, Value Co-Creation by Customer-to-Customer communication: Social media and Face-to-Face for case of airline service selection, Journal of Service Science and Management (2012), no. 5, 101-109.

[4] B. C. A. S. Pace and P. S. le N, Brand volunteering: Value co-creation with unpaid consumers, Marketing Theory 4 (2015), no. 15, 465-485.

[5] S. Pongsakornrungsilp and J. E. Schroeder, Understanding valueco-creation in a co-consuming brand community, Marketing Theory 11 (2011), no. 3, 303-324.

[6] S. L. Vargo and R. F. Lusch, Service-dominant logic: Continuing the evolution, Journal of the Academy of Marketing Science 36 (2008), no. 1, 1-10.

[7] Y. Wang, Brand image, perceived quality,perceived value and purchaseintention -- an example of awarded funds, Advances in Investment Analysis and Portfolio Management 7 (2016), 215-235.

[8] S. Wikstro M, The customer as co-producer, European Journal of Marketing 30 (1996), no. 4, 6-19. 